\title{
Guns and/or Butter: The Relationship between the Economy and the Military
}

\author{
Raphael Kaplinsky
}

\section{Uneven Development: a Change in Growth Poles}

The uneven path of industrial accumulation has long been noted, being occasioned by a variety of different causal factors, including the geographical incidence of natural resources, radical changes in technology and patterns of social relations which are out of tune with the evolving characteristics of best-practice production systems. This is not the place to rehearse these and other competing explanations for a change in the 'economic centre of gravity' - see rather a number of the contributions in IDS Bulletin vol $16 \mathrm{no} \mathrm{l}$-but it is worth pointing to two key developments in the pattern of post-war economic growth. First, the three decades after the war were years of historically unprecedented economic progress, characterised by Maddison as the 'Golden Age' [Maddison 1982]. Not only was this a period of almost unprecedented boom, but it took place within the context of a disproportionate expansion in world trade. International exchange and competition in this period became a dominani irend in almost all economies, even in large, resource-endowed economies such as the USA. And secondly, the victors of the Second World War - notably the USA and the UK - seem to have performed significantly worse over this period than their competitors.

At issue in this discussion is the possibility that this unusual pace of economic growth and its uneven character can in some significant sense be related back to the extent of resources devoted to the military sector. This of course is a subject of enormous complexity which, curiously, has received scant attention. There are, for example, less than 10 economists in the whole of the UK who currently devote themselves to exploring this topic. There can be no question of providing a full discussion of the major theoretical relationships between the economy and the military sector in this short article (some of which are to be found in the contribution by Deger and Smith in this Bulletin). Instead I shall be confining my remarks to some speculations on the relationship between military expenditure and innovation in the two major laggard OECD economies - the UK and the USA. In this I will be able to consider both positive and negative effects, and in so doing point to some notional balance of the net impact on innovation. I shall also briefly consider some of the factors conditioning the extent to which military expenditure has acted as a Keynesian multiplier, facilitating the expansion of the economy in an era of underutilised resources.

The discussion which follows hinges on one key observation and one set of key assumptions. The observation is that in this post-war period of unprecedented growth there has been a (statistically) negative correlation between the volume of national income devoted to military expenditure and the rate of economic growth (see Figure 1 for the broad aggregates and DeGrasse 1982 and Smith 1980 for the statistical results). Prima facie this suggests a causal interaction, a conclusion which will receive attention below. The analytical assumptions underlying my speculations are of a Schumpeterian nature, assuming that innovation lies at the heart of economic growth. Moreover, in an era of falling profits [Hill 1979] and increased competition, the ability of a country to innovate rapidly and effectively will determine the extent to which it becomes a laggard or a leader in the growth-stakes. By this count, at one end of the spectrum Japanese and German firms have consistently innovated effectively, and American and British firms have conversely been extremely poor innovators. Whilst innovation clearly reflects the quality of management and other factors (including the macroeconomic environment), in an era of increasingly science-based production, R\&D and technological progress are obviously of key significance.

\section{The Military and Technological Progress: Some Positive Spin-offs}

There can be no question that the vast amount of resources committed to defence expenditure in the 
Military Burden, Growth, Investment, and Productivity 1960-1979

\begin{tabular}{|c|c|c|c|}
\hline $\begin{array}{c}\text { Miliary Spending as } \\
\text { Proportion of Gross } \\
\text { Domestic Product } \\
G D P(\%)\end{array}$ & $\begin{array}{c}\text { Real Rate of Grovith } \\
\text { in } G D P(\%)\end{array}$ & $\begin{array}{c}\text { Grost tived Capital } \\
\text { Investment as } \\
\text { Proportion of } \\
\text { GDP (\%) }\end{array}$ & $\begin{array}{c}\text { Growth in } \\
\text { Manufacturing } \\
\text { Productivity (\%) }\end{array}$ \\
\hline
\end{tabular}

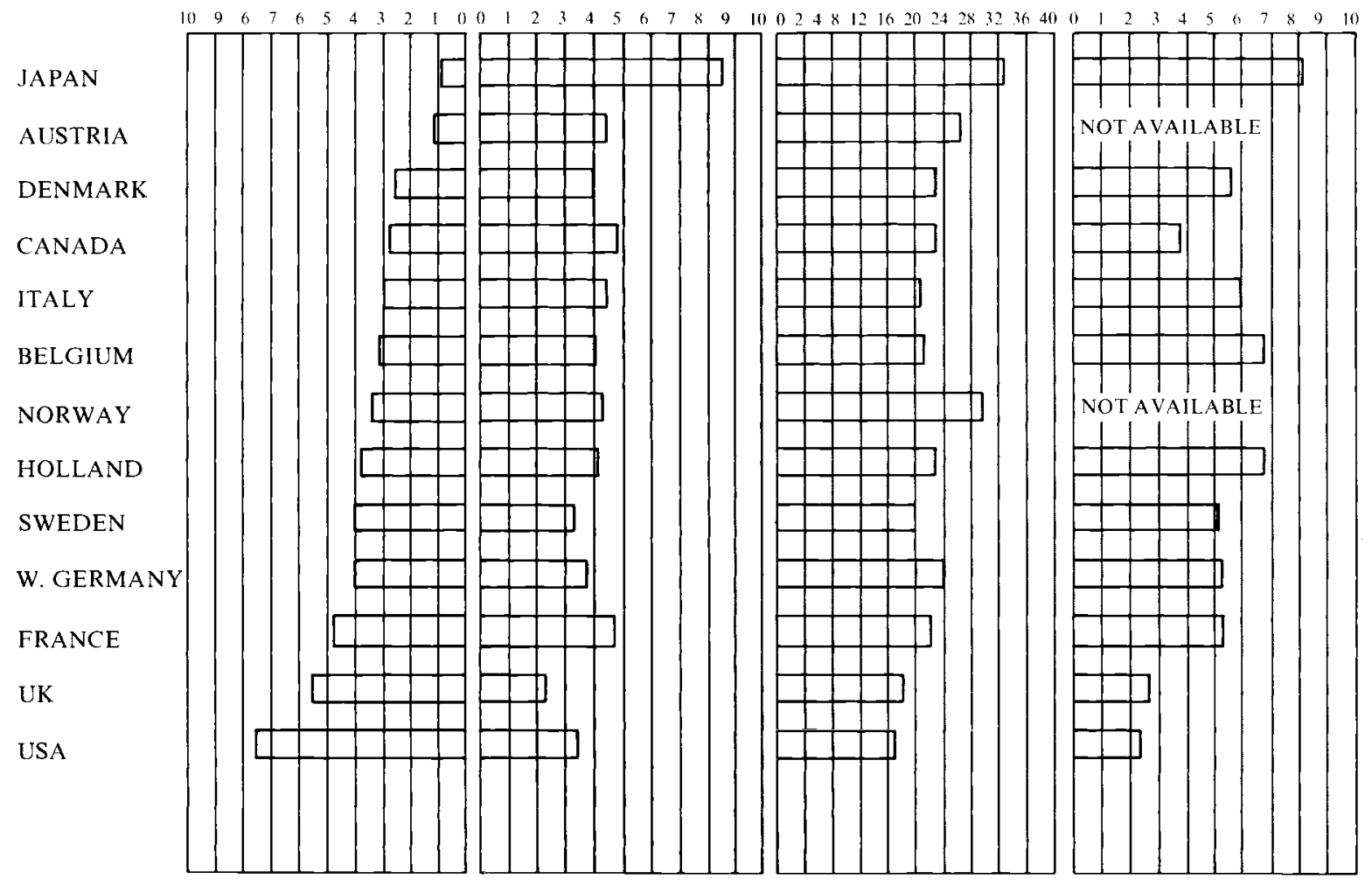

Source: De Grasse 1982: 15

USA and the UK ${ }^{1}$ has had a positive effect on the economy and technology - at question is the net economic impact. These spin-offs have been far more evident in the USA than in the UK. Confining ourselves to technological progress in the USA it is possible to point to three major developments in which the Department of Defense (DoD) has played a key role as procurer, funder and motivator. The first concerns the development of the integrated circuit in the 1960s and 1970s, a key technological development which happened to be of particular importance in the

\footnotetext{
Between 1979 and 1983. military expenditure grew in real terms in the UK at 2.9 per cent pa, reaching a level of 5.3 per cent of GDP in 1983. In the same period, military expenditure in the US grew at around 6 per cent pa culminating in a share of 6.9 per cent of GDP.
}

military's drive towards miniaturisation after the US had been upstaged by the launch of Sputnik in 1957. Not only did the DoD fund some of this development, but more importantly it paid a high price for the circuits and provided a secure market. After this developmental period in which the technology was tested and proved, the proportion of integrated circuits sold to the military fell from 70 to 7 per cent between 1965 and the late 1970s [USOTA 1983]. A second example comes from the Man/Tech (Manufacturing Technology) programme and its predecessors, which includes the ICAM (Integrated Computer Integrated Manufacturing) scheme. (The resources devoted to this scheme are shown in Table 1.) This was responsible for the initial development of numerically controlled (NC) machine tools in the late 1940s and 
Funding for the US DoD Man/Tech scheme (\$ mn)

\begin{tabular}{lcccr}
\hline & 1980 & 1981 & 1982 & 1984 \\
\hline Army & 68 & 76 & 95 & 86 \\
Navy & 14 & 12 & 29 & 57 \\
Air Force & 56 & 66 & 86 & 57 \\
IMIP* & - & - & - & 83 \\
Total & 138 & 154 & 210 & 283 \\
\hline
\end{tabular}

IMIP Industrial Modernization Incentives Program

Source: van Tulder 1985

early 1950 s to machine helicopter rotors and complex wing subframes. Subsequently the DoD provided grants and soft-loans to manufacturing industry to encourage them to adopt this technology. Currently, $\mathrm{NC}$ is the basic building block in electronics-based factor automation. The third and final example is drawn from the development of computer-aided design (CAD) technology which had its origins in the early-warning missile alert system in the 1950s. This CAD technology is of fundamental importance in the electronics sector and is of increasing competitive significance in manufacturing and other sectors. Thus, in acknowledging the role played by the military in the development of these three technologies, we should be aware that they are of great significance to the contemporary emergence of computer integrated manufacturing.

\section{The Opportunity Cost}

The very role played by the military in the development of these three technologies immediately highlights the problem of opportunity cost. In the case of integrated circuits, American dominance vis à vis Japan is on the verge of being lost. Moreover, in the primary downstream use of these products - in consumer goods - American producers were elbowed out of global markets during the 1970s. And in one area in which US firms have been dominant - office automation - the portents for their competitive superiority seem bleak. Similarly, in the case of NC, US firms have fared particularly badly in comparison with Japanese and European producers and are increasingly threatened by the more advanced NICs. Only in respect to CAD technology can it be said that the impetus provided by military expenditure has been translated into market dominance.
The position of the UK is even more representative of these trends. Here too, the Ministry of Defence (MoD) provided extensive resources for the development of $\mathrm{NC}$ machine tools and computing. NC machine tool production in the UK now appears to be on its last legs, whilst in the case of minicomputers in which the UK was an early producer, it has been shown that reliance on the miltary market - with high specifications and knowledgeable users - meant that producing firms were inappropriately oriented to a civilian market which was made up of inexperienced users of cheaper, general machines [Sciberras et al. 1978].

The argument is that production for the military induces biases in products which make them inappropriate for the much larger civilian sector. The military requires 'goldplating' standards, a factor pointed to by a former UK government Chief Scientist in his investigation of why there had been so few spin-offs from the military to the civilian sector in the UK [Maddock 1984]. Moreover it also makes intensive use of highly skilled human resources, and in an era in which production is increasingly technologybased it tends to bleed the civilian sector of these skills. This conclusion was reached not only by Sir Ian Maddock, but also by a comprehensive study of falling UK industrial competitiveness in the late 1970s [Pavitt et al. 1981] and by recent studies in the USA [De Grasse 1984]. Most pertinently, the problem of opportunity cost has been highlighted by the chairman of Sharp, one of the largest Japanese electronic firms. He remarked of a joint venture between his firm and an American counterpart (Rockwell) to produce a microprocessor in the early 1970s, that while Sharp had used the circuit to dominate the hand-held calculator market, Rockwell had used the same 
product for the guidance system in the Apollo moonprobes [Baba 1985].

\section{The Distortion of $\mathbf{R} \& \mathrm{D}$}

Since, as we have remarked above, modern production technology is increasingly science-based, $\mathrm{R} \& \mathrm{D}$ is an important element of competitive performance. Quite obviously the nature of this R \& D is as crucial as its extent. Aggregate expenditures for the various OECD economies are particularly interesting here. Whilst the UK and the USA have consistently spent a greater proportion of their GDP on $R \& D$ than their rivals over the past few decades, once the large share devoted to military needs is withdrawn, the performance of these two economies has been relatively poor. ${ }^{2}$ The picture is particularly alarming for the UK electronics sector where the proportion of $\mathrm{R} \& \mathrm{D}$ going to military needs is around two-thirds. At the same time we see our largest corporations in this sector, such as General Electric, Racal, Ferranti and even British Aerospace, increasingly withdrawing from the civilian to the military sector.

The same process of distortion is currently being played out in the USA in regard to the DoD's Very High Speed Integrated Circuit (VHSIC) programme which is designed to produce circuits able to withstand the electro-magnetic pulse (EMP) of nuclear explosions, which with current silicon technology will make most existing electronic components virtually unusable. It is also evident in the case of US government support of Information Technology artificial intelligence research in which DoD funds account for between 70 and 80 per cent of all federal funds. The VHSIC programme absorbed 35 per cent of all government integrated-circuit related R \& D in 1981 and 1982, despite the conclusion of an official assessment team that the programme diverted resources from other civilian related programmes without either the firms or the government steppingup their overall $R \&$ D efforts [cited in OECD 1984]. In the case of support for artificial intelligence $R \& D$ - one of the cornerstones of Japan's Fifth Generation computer project and the UK's Alvey Programme - a report by the US Office of Technology Assessment concluded that:

Science policy experts interviewed by OTA were almost universally concerned about the resurgence of DoD funding for $R \& D$, for information $R \& D$ in particular. Comparing the current situation to the post-war era when DoD research funding was also dominant, they point out that current research

\footnotetext{
2 The share of military R\&D in total government R\&D in 1983 was 64.1 per cent for the US. 50 per cent for the UK. 33 per cent for France. 9.4 per cent for West Germany and 6.1 per cent for Italy [SIPRI 1984].
}

is generally much more mission-oriented and, consequently, less productive for nonmilitary users [USOTA 1985: 296].

\section{Military Expenditure as a Keynesian Multiplier}

One of the primary contributions of Keynesian economics is the recognition that when resources are underutilised, deficit expenditure by government can lead to economic growth and a higher utilisation of resources through the operation of a multiplier. The military - one sector in which the state is almost entirely responsible for the quantum of resources potentially offers precisely these prospects. Moreover, as Kalecki argued about the 1930s, there are reasons why the priming of the economic pump via military expenditure faces fewer political obstacles from the business class, than if resources are expended in other sectors [Kalecki 1972]. Indeed, some argue that since 1979 it has precisely been the massive increase in military expenditure in the USA ${ }^{3}$ which has reflated the US economy and stimulated global economic growth in the short run. Of course this is a complex discussion and I make no pretence of doing it full justice here. I will, however, offer two reasons why I think it unlikely that military expenditure is an optimal route - even from the narrow perspective of economics - for pump-priming of the economy.

The first concerns the generation of employment through state expenditure. Here the multiplier operates through the expansion of demand following increased incomes to the newly employed. There are dual reasons why the military-multiplier is less effective than alternatives, especially those of an infrastructural nature. In the first place there is clear evidence that production for this sector is highly capital intensive. In the US, for example, it has been estimated that the number of jobs created by the expenditure of $\$ 1$ bn (1980 dollars) was 29,402 for missile production, 45,397 for mass transit, 36,650 in public utilities, 31,819 in railroads, 30,899 for housing and 38,192 for solar energy or energy conservation. In the UK it has been estimated through the use of the Warwick macroeconomic model of the economy that a reduction in the military/GNP ratio to that Western European NATO average would - assuming that half of this redirected finance would go on investment and half on recurrent expenditure - have an overall impact of creating an additional 100,000 jobs [Smith 1980]. Equally important, probably, is the fact that military expenditure - especially outside the USA - appears to be much more import intensive, so that the multiplier effect tends to be felt abroad rather than domestically.

\footnotetext{
${ }^{3}$ Between 1979 and 1983. US military expenditure grew from $\$ 111.8$ bn to $\$ 221.5 \mathrm{bn}$. an increase in real terms of 33 per cent. In the UK in the same period it grew from $\$ 8.9$ bn to $\$ 16.8$ bn. a real growth of 23 per cent [Smith 1985].
} 
A second reason for questioning the efficacy of military expenditure as a Keynesian multiplier arises out of a closer look at the nature of unemployed resources. It is true that levels of unemployment in all of the OECD economies are much higher now than in the three decades after World War II. In some cases - especially when account is taken that rise in unemployment which has been hidden in redefined categories such as 'youth employment programmes' and 'retraining programmes' - the current rate of unemployment is higher than that which prevailed at the height of the Great Depression in the 1930s. Yet at the same time, in relation to highly skilled human resources, there are acute shortages. One study calculated that whilst American universities would produce 70,000 electrical engineers between 1982 and 1985 , the economy would require around 200,000 [USOTA 1983: 320]. It is precisely in these areas that the military and civilian sectors compete for resources, and if anything the military is a more intense user than the civilian. ${ }^{4}$ Similar observations could be made for scarce intermediates - such as during the 'chipfamine' in 1983-84 - and capital goods. Hence the expansion of demand through military expenditure is likely very rapidly to run into bottlenecks such as these - even whilst mass unemployment is growing - and is hence an economically sub-optimal way of stimulating demand.

\section{Correlation and Causality}

I have observed that there appears to be a close and inverse relationship between the proportion of GNP spent on the military and the rate of economic and productivity growth. I have also run through a number of points which illustrate how it is that despite spin-off from military expenditure, its overall effect is to divert resources from the highly-competitive civilian sector. Yet the fundamental question arises of whether, in the countries under consideration, military expenditure has grown because the civilian industries were uncompetitive, or whether civilian industries were rendered uncompetitive by the call from the military. Both alternatives require shifting the analysis from the economic domain to that of political economy. This is useful because it allows us to shift more meaningfully into a brief discussion of the problems of conversion. Let us begin by briefly examining each of the two causal threads.

The argument that military expenditure has been a response - albeit misguided - to declining economic competitiveness has its roots in a more historical form of analysis. British industrial decline goes back to the last quarter of the nineteenth century; American

${ }^{4}$ In the UK the percentage of military equipment procurement on electronics grew from 17.5 to 21.5 between $1979-80$ and 1983-4 [Smith 1985]. economic decline, with its roots in the increasing inappropriateness of Fordist labour processes, goes back to the 1950s. In each case, their host TNCs found it increasingly difficult to compete first in global markets and subsequently in domestic markets. The response was to retreat into the protected domain of state procurement, and nowhere is this more possible than in the case of military procurement. The retreat by the component parts of what has become British Aerospace from civilian to military and aerospace products is a case in point. This has been highlighted in recent months by the attempt by two of the ailing giants of the UK electronics industry - General Electric Company and Thorn-EMI - to take over British Aerospace and so get access to its protected military sales. Similarly, the recent purchase by General Motors in the USA of Hughes Aircraft for $\$ 5$ bn represents an attempt to escape from the competitive strength of Japanese and European automobile producers. This form of analysis leads us towards seeing the state as an instrument, to be played by domestic capital in its search to escape the competitive pressures of the global market. The fact that for most of the post-war period contracts to government in both countries have been on a cost-plus basis - thereby guaranteeing profits and perhaps also inefficiency - strengthens the argument further.

And yet the recent turnaround in the UK in which the state has begun to force lower profit-margins on its suppliers, suggests that some weight must also be given to the possibility that when the state has come to be dominated by external military pressures or by its own internal military lobby, it has forced the pace with the industrial sector, inducing it to divert scarce resources to meet military needs. The VHSIC programme mentioned above, in which US electronics firms are being pressured against their will to partake in the state-assisted scheme, is a case in point.

In actual fact neither of these explanations alone explains the close link between declining competitiveness and military expenditure. Both need to be taken into account, involving some form of dialectical interplay between them. It is this which has led some observers to focus on the 'military-industrial complex', or as one recent American observer has termed it [Adams 1982], the 'iron triangle', involving extremely close links between senior civil servants, the military and the captains of industry. In the UK the recent appointment of Mr. Peter Levene - formerly head of a major defence contractor, United Scientific Holdings (USH) - as head of procurement at the Ministry of Defence, and his replacement at USH by the former MoD permanent secretary suggests that the process is not unique to the USA. Moreover, in the US these close military-industrial links have been mediated through lobbyists, and it is a source of some 
concern that professional lobbying of this sort is becoming increasingly evident in the UK. An understanding of this is especially important if serious attention is to be given to the prospects for conversion, a subject with which I conclude my discussion.

\section{Conversion: The Policy Implications}

If it is true that the vast resources devoted to the military sector are - economically speaking - an inefficient way of meeting demands for economic growth, then it is clear that some reorientation of priorities is necessary. The observation that the level of resources devoted to the military sector must find its explanation in political-economy serves only to point out that, left on their own, 'market forces' are unlikely to lead to a reorientation of priorities. Moreover, the sheer scale of these expenditures ensures that such a shift would require careful managing. For example, merely to reduce UK military expenditure to the Western European NATO average would provide an additional $£ 5.5$ bn a year, equivalent to over twothirds of the Government's public sector borrowing requirement! Assuming that this money were to be diverted elsewhere - for if not, there is sure to be an economic deflator in reduced military expenditures - there is a need to carefully consider the alternatives.

It is this which has focused attention on the problems of 'Conversion', that is, providing a suitable policy framework for the redirection of resources. It is often implied that this is unmanageable - that if the Trident programme is cancelled, for example, no alternative employment will be available for the redundant Barrow-in-Furnace workers. It is important for the future economic well-being of our society that this negative conclusion should be refuted. The fact is that significant conversion has occurred three times in the UK since the Second World War. The most recent occasion has been over the past six years in which we have seen a process of conversion, but this time from the civilian to the military sector rather than vice versa. This has occurred whilst the British government has expanded military spending by three per cent a year and at the same time has cut back other programmes with a more direct industrial impact (such as the recent decisions to scale down regional investment incentives, subsidies on exports of capital goods and the microelectronics-adoption support programmes). A second example of conversion comes from the immediate post-war period. Then the British economy successfully diverted $3.5 \mathrm{mn}$ people from munitions production, and a further $4.3 \mathrm{mn}$ from the armed services. The proportion of GDP spent on the military declined from more than 50 to 7.5 per cent in the course of five years. And finally, in the postKorean War period, the Conservative government reduced the proportion of GDP spent on the military by the same percentages -2.2 - as that which would be involved if the UK currently reduced its commitment to the same level as its Western European NATO partners.

I believe that, on balance, we can draw four major conclusions from these brief thoughts. The first is that despite the existence of some positive spin-offs, military expenditure diverts from economic competitiveness as well as making the achievement of fuller employment more difficult. Secondly, the underlying roots of this high military expenditure in the relatively laggard OECD economies is to be found in the realm of political-economy, pointing to the cohesive and comfortable relationship between uninnovative firms, military pressure groups and the state itself. Third, despite emotive exhortations to the contrary, the lesson arising out of historical analysis is that conversion is possible. It is a matter of political will. And, finally, it should be obvious that whilst this discussion has been couched in terms of the economic rationale of military expenditure, there are clearly other political and moral reasons for reducing its role in contemporary economic life. It is merely convenient that economic factors tend to reinforce what is painfully obvious.

\section{References}

Adams, G., 1982, The Politics of Defense Spending: The Iron Triangle, Transaction Books, London and New Brunswick

Baba, Y., 1985, 'Japanese Colour TV Firms' Decision Making from the 1950s to the 1980s: Oligopolistic Corporate Strategy in the Age of Microelectronics', DPhil dissertation, University of Sussex

De Grasse, 1982, The Costs and Consequences of Reagan's Miliary Build-Up, Council on Economic Priorities, Washington

Hill, P., 1979, Profiu Shares and Rates of Relurn by Country, OECD, Paris

Kalecki, M., 1972, 'The political aspects of full employment' (1943) in The Last Phase in the Transformation of Capiralism, Monthly Review Press, New York

Maddison, A., 1982, Phases of Capilalist Development, Oxford University Press

Maddock, I., 1983, Civil Exploiration of Defence Technology, Electronics EDC, NEDC, London

OECD, 1984, Trade in High-Technology Products: The Semiconducior Industry, Paris

Pavitt, K. (ed), 1981, Technical Innovation and Brilish Economic Performance, Macmillan, London 
Scriberras, E., N. B. Swords-Isherwood and P. J. Senker, 1978, 'Technical change and manpower in electronic capital equipment: a study of the UK minicomputer industry', Occasional Paper No. 8, Science Policy Research Unit, University of Sussex

Smith, R. P., 1980, 'Military expenditure and investment in OECD countries 1954-1973', Journal of Comparative Economics

Smith, R., 1985, 'The significance of defence expenditure in US and UK national economies', Built Environment (in press)
SIPRI, 1984, World Armaments and Disarmament, Taylor and Francis, London, for the Stockholm International Peace Research Institute

Van Tulder, R., 1985, 'Towards Increased Convergence: International Interaction in Subsidy Policies for CAD/CAM', University of Amsterdam (mimeo)

US Office of Technology Assessment, 1983, Information Technology R\&D: Critical Trends and Issues, Washington -1985, International Competitiveness in Electronics. Washington 